Communications in Physics, Vol. 24, No.3S1 (2014), pp. 1-6

DOI:10.15625/0868-3166/24/3S1/5070

\title{
NON-DESTRUCTIVE CHARACTERISTICS OF ULTRASONIC WAVES IN 1018 LOW CARBON STEEL
}

\author{
DO TRUNG KIEN, PHAM THI TUYET NHUNG, PHAM VAN THANH \\ Faculty of Physics, University of Science, Vietnam National University, Hanoi \\ E-mail: phamvanthanh@hus.edu.vn
}

Received 20 June 2014

Accepted for publication 20 August 2014

\begin{abstract}
In this paper, the dependences of the velocities and the absorption coefficients of ultrasonic waves transmitted in 1018 low carbon steel on temperature ranging from $0^{\circ} \mathrm{C}$ to $50^{\circ} \mathrm{C}$ were investigated. It was shown that the velocities of the ultrasonic longitudinal wave and ultrasonic shear wave were decreased when the temperature increased. The transportation of the ultrasonic longitudinal wave and ultrasonic shear wave depends on temperature and its coefficient in a temperature range of $\left(0-50{ }^{\circ} \mathrm{C}\right)$ was estimated about $0.8 \mathrm{~m} / \mathrm{s} .{ }^{\circ} \mathrm{C}$ and $0.44 \mathrm{~m} / \mathrm{s} .{ }^{\circ} \mathrm{C}$, respectively. These obtained results are in good agreement with the theoretical prediction. Furthermore, the absorption coefficients of the ultrasonic longitudinal wave were also studied.
\end{abstract}

Keywords: ultrasonic, nondestructive testing, longitudinal wave, shear wave, ultrasonic velocity, attenuation, low carbon steel.

\section{INTRODUCTION}

Non-destructive testing methods are very popularly used to evaluate the properties of materials, components or systems without damages. The most common application is checking of defects. When the defects are detected, their location, dimension, orientation, and shape are required to determine. Other important characteristics are also required by using the nondestructive testing methods, such as micro-structural and mechanical properties. There are several non-destructive techniques, such as X-ray images [1], thermographic imaging [2], ultrasonic testing methods [3], etc.... In these methods, the ultrasonic testing method is widely used to analyze and characterize the properties of materials [4-7].

Recently, carbon steels have many applications in different fields such as ship building, goods fabrication, home appliances, ship sides, low carbon wire, etc...the reason for these popular applications is due to the good properties of this steel material such as its good strength, good toughness and ductility [8]. A. Ruiz et al used the ultrasonic method for early detection of thermal damage in steel [9], Vera Lúcia de Araújo Freitas et al showed that the nondestructive characterization of microstructures and determination of elastic properties of the carbon steel can be utilized by the ultrasonic method [10]. In addition, Changzhou Yan et al and Liu Zenghua et al reported 
the dependence of the ultrasonic properties of steels on temperature $[11,12]$. Therefore, the ultrasonic non-destructive testing is useful method to analyze and characterize properties of carbon steel.

The main aim of this work is to evaluate the dependence of properties of ultrasound in 1018 low carbon steel on temperature. By using the pulse echo technique and the direct contact method of ultrasonic nondestructive testing, velocities of ultrasonic longitudinal wave and ultrasonic shear one were characterized when temperature changes from 0 to $50^{\circ} \mathrm{C}$. Simultaneously, the dependence of the attenuations of ultrasonic longitudinal wave on temperature of this steel sample was also analyzed. These characteristics of the ultrasonic waves in the 1018 low carbon steel have not yet reported before.

\section{EXPERIMENTAL METHODS}

Type 1018 low carbon steel was used in this study with the following chemical composition in \%wt: $0.17 \mathrm{C}, 0.816 \mathrm{Mn}, 0.01 \mathrm{P}, 0.005 \mathrm{~S}$, $0.07 \mathrm{Ni}, 0.06 \mathrm{CR}, 0.01 \mathrm{Mo}, 0.2 \mathrm{Cu}, 0.022 \mathrm{Al}$, and $0.01 \mathrm{~N}$. The mass density of this steel type is $7800 \mathrm{~kg} / \mathrm{m}^{3}$. The shape of this steel sample was shown in Fig. 1 with $\mathrm{mm}$ unit for each dimension, this sample was separated into two parts: one for ultrasonic longitudinal wave measurement and other for ultrasonic shear wave measurement.

Fig. 2 shows the schematic diagram of the experimental set-up. In this diagram, the Ultrasonic Flaw Detector AD 3213EX was used as a pulser/receiver ultrasonic system [13], the pulse echo technique and direct contact method were used to characterize the ultrasonic velocity and the attenuation parameters. A single transducer with $5 \mathrm{MHz}$ center frequency was used to generate an ultrasound and then receive echo for the ultrasonic longitudinal wave; otherwise, a single $45^{\circ}$ angle transducer with $5 \mathrm{MHz}$ center frequency was used for ultrasonic shear wave measurements. Viscous oil was used as a coupling material between transducers and steel sample. The temperature of sample was measured and recorded by using a data logger system with the accuracy of $\pm 0.5^{\circ} \mathrm{C}$ [14], and was also mea-

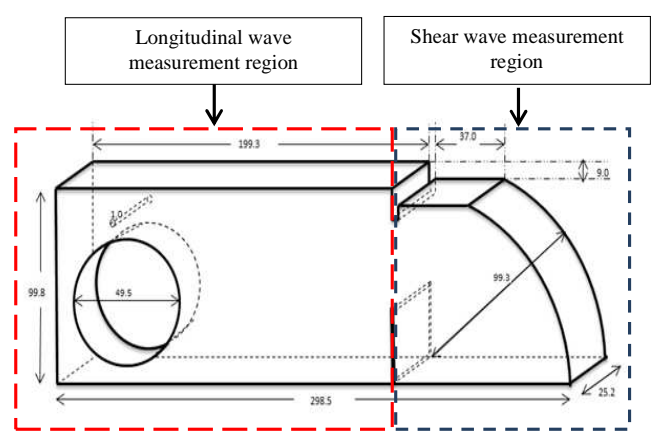

Fig. 1. The dimensions of 1018 steel sample

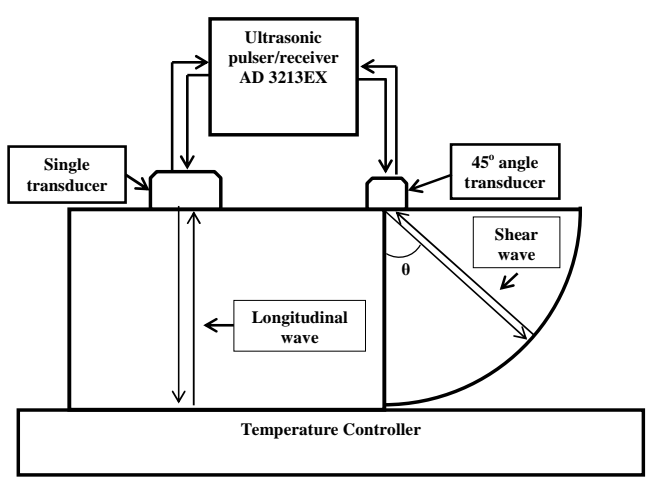

Fig. 2. Schematic diagram of the experimental set-up sured by thermometer TM-902C as a comparison for accuracy of this data logger system. 


\section{TEMPERATURE DEPENDENCE OF ULTRASONIC WAVE PROPAGATION}

The mechanical properties and dimensions of a steel sample will change because of its temperature dependence. A linear dependence of each property on temperature is assumed as following equation $[12,15,16]$ :

$$
P(T)=P\left(T_{0}\right)+\frac{\partial P(T)}{\partial T} \Delta T,
$$

where $P$ is one of the mechanical properties of sample, such as Young's modulus $E$, Poisson's Ratio $v ; \quad T$ is sample's temperature, $T_{0}$ is reference temperature, and $\frac{\partial P(T)}{\partial T}$ is temperature dependence coefficient, i.e., sensitivity of the material property of sample to temperature.

Furthermore, the dependence of ultrasonic wave velocities on temperature can be obtained by following relations $[10,16]$

$$
\begin{gathered}
C_{\text {longitudinal }}=\sqrt{\frac{E(1-v)}{\rho(1+v)(1-2 v)},} \\
C_{\text {transverse }}=\sqrt{\frac{E}{2 \rho(1+v)}},
\end{gathered}
$$

where $C_{\text {longitudinal }}$ and $C_{\text {transverse }}$ are velocity of ultrasonic longitudinal wave and one of ultrasonic shear wave, respectively; $\rho$ is mass density of material.

If the temperature of steel sample is smaller than $500^{\circ} \mathrm{C}$, the dependence of Young's modulus E on temperature expressed in Eq. (1) is almost linear and shown in Fig. 3 [8]. From linear fitting of this dependence, the sensitivity of $E$ to the temperature, i.e., $\frac{\partial E(T)}{\partial T}$, is $-0.0803 \mathrm{GPa} /{ }^{\circ} \mathrm{C}$; and one of the Poisson's ratio $v$, i.e., $\frac{\partial v(T)}{\partial T}$, is $2.4 \times 10^{-5}$ $/{ }^{\circ} \mathrm{C}[8],[12]$; simultaneously, the sensitivity of the linear thermal expansion to the temperature is $1.2 \times 10^{-5} /{ }^{\circ} \mathrm{C}$ [8]. Because this thermal expansion is small, the temperature dependence of mass density $\rho$ of this sample will be ignored, (thus considered as constant value of

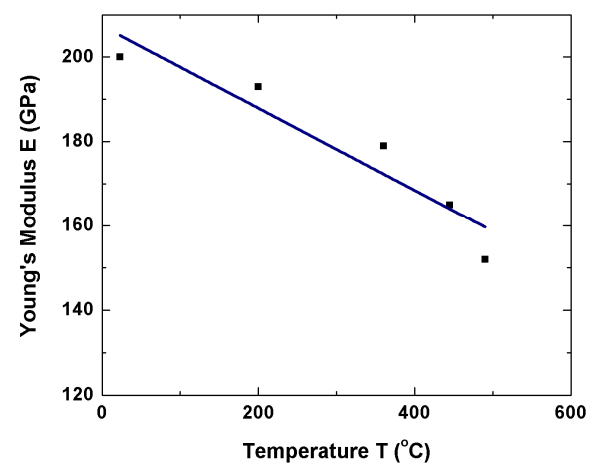

Fig. 3. Young's Modulus E vs Temperature $\mathrm{T}$ of 1018 carbon steel $7800 \mathrm{~kg} / \mathrm{m}^{3}$ within a range from 0 to $50^{\circ} \mathrm{C}$ ). Moreover, the values of $E$ and $v$ of 1018 carbon steel were $200 \mathrm{GPa}$ and 0.3 at $23^{\circ} \mathrm{C}$, respectively [8]. Therefore, based on Eq. (2) and Eq. (3), the theoretical velocities of longitudinal wave and shear one can be obtained.

\section{RESULTS AND DISCUSSION}

From the Eq. (1) and Eq. (2), it is clearly that the velocity of ultrasonic longitudinal wave strongly depends on temperature of material. Based on the properties of 1018 low carbon steel described above, the theoretical velocities of the ultrasonic longitudinal wave vs temperature were 
obtained

and shown in line

(a) of Fig.

4.

These velocities were calculated to be in the range of 5894 to $5931 \mathrm{~m} / \mathrm{s}$ when the temperature of sample changed from 0 to $50^{\circ} \mathrm{C}$, and their values are almost linear according to the temperature. It can be seen that the coefficient of temperature dependence of longitudinal velocities is $-0.97 \mathrm{~m} / \mathrm{s} .{ }^{\circ} \mathrm{C}$. Simultaneously, by using A-scan of pulse/echo method of the ultrasonic non-destructive testing [3], the velocities of the experimental ultrasonic longitudinal were also obtained and shown as line (b) of Fig. 4; these velocities increased in the range of 5894 to $5931 \mathrm{~m} / \mathrm{s}$ when temperature decreased from 50 to $0{ }^{\circ} \mathrm{C}$, these obtained velocities are very close with the theoretical ones. The coefficient of temperature dependence of these experimental velocities was obtained to be $-0.80 \mathrm{~m} / \mathrm{s} .{ }^{o} \mathrm{C}$ by using the linear fitting, this value is also quietly close to $-0.97 \mathrm{~m} / \mathrm{s} .{ }^{o} \mathrm{C}$ of theoretical one. Furthermore, these theoretical and experimental velocities are comparable with ones of other researches $[9,10,12]$, thus these obtained velocities are very reliable.

Otherwise, based on Eq. (1) and Eq. (3), the ultrasonic shear velocities also depend very much on the temperature of material. This dependence was clearly obtained in the range of 3176 to $3149 \mathrm{~m} / \mathrm{s}$ and shown as line (a) of Fig. 5, it is almost linear and its temperature dependence coefficient was calculated to be

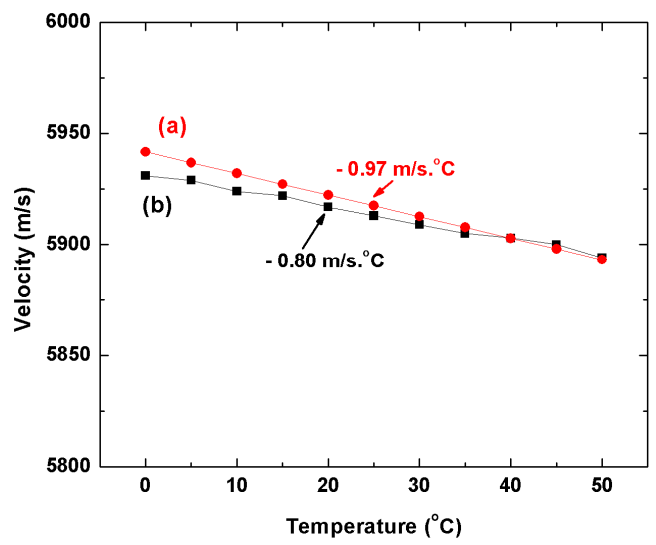

Fig. 4. The theoretical velocity [line (a)] and experimental one [line (b)] of ultrasonic longitudinal wave vs temperature

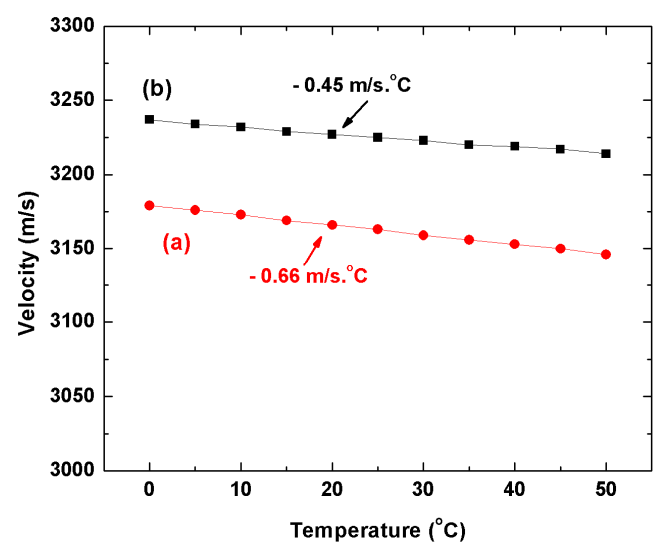

Fig. 5. Theoretical velocity [line (a)] and experimental one [line (b)] of ultrasonic shear wave vs temperature $-0.66 \mathrm{~m} / \mathrm{s} .{ }^{o} \mathrm{C}$ by using the linear fitting. The experimental velocities of this ultrasonic shear wave were also investigated in the range of 3214 to $3237 \mathrm{~m} / \mathrm{s}$ and shown as line (b) of Fig. 5. Based on the linear fitting of these results, the coefficient of the thermal dependence of these experimental ultrasonic shear velocities was calculated to be $-0.44 \mathrm{~m} / \mathrm{s}$. ${ }^{\circ} \mathrm{C}$. It is clearly shown that the shear velocities have smaller temperature sensitivity than that of the longitudinal velocities for both case of theoretical and experimental ones. These experimental results are also close to the theoretical ones and they are comparable with the results of other researches [10-12]. 
In addition, the attenuation coefficient of the ultrasonic waves in specimen can be obtained by measuring the peak amplitude of the echoes from observed time domain traces by following the relation $[17,18]$

$$
\alpha=\frac{-20}{2(m-n) d} \log \left(\frac{I_{m}}{I_{n}}\right),
$$

where $I_{n}$ and $I_{m}$ are the maximum amplitude of the $\mathrm{m}^{\text {th }}$ and $\mathrm{n}^{\text {th }}$ pulse echoes, $\mathrm{d}$ is the thickness of sample.
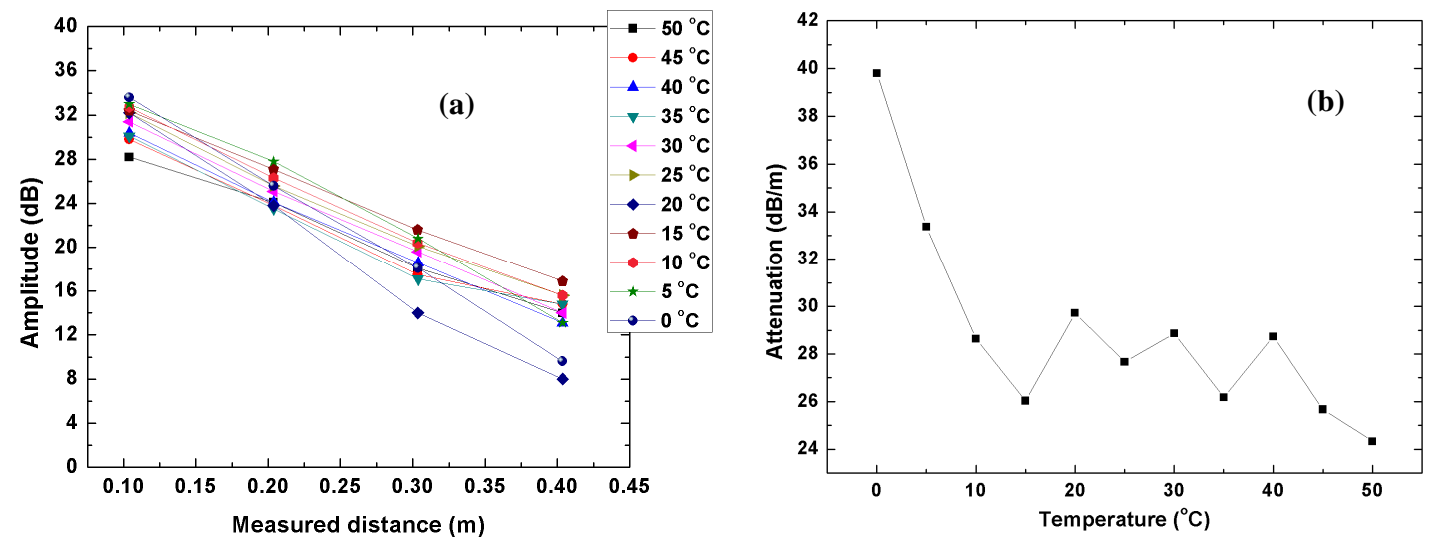

Fig. 6. (a) Amplitude vs measured distance curves in the range of 0 to $50{ }^{\circ} \mathrm{C}$ of temperature, and (b) the attenuation vs temperature

Fig. 6(a) shows the dependence of amplitude of ultrasonic longitudinal wave when the measured distance changes from 0.1 to $0.4 \mathrm{~m}$ corresponding to the $1^{\text {st }}$ echo to $4^{\text {th }}$ echo, respectively. Based on the Eq. (4), the values of attenuation vs temperature of sample were calculated and shown in Fig. 6(b). This dependence of attenuation on temperature is very complicated. Many factors can contribute to this dependence. P. Palanichamy et al showed that the attenuation of the ultrasonic beam is influenced by the grain size of steel [19], M. Molero et al though that the attenuation must be effected by the frequency of the ultrasonic wave [18], Devraj Singh et al showed that the attenuation of ultrasonic longitudinal wave depended on $C_{\text {longitudinal }}^{-3}$ [7], while N. Guo et $a l$ and ER. Generazio considered that the attenuation of ultrasonic beam is influenced by the thickness of the coupling material in the direct contact technique and unsteady pressure applied to the transducer and roughness [20]. In this research, it is believed that the curve of the attenuation vs temperature can be separated into two part: the first part corresponds to the temperature in the range of 0 to $15^{\circ} \mathrm{C}$ and the second part corresponds to the temperature range from 15 to $50{ }^{\circ} \mathrm{C}$. In the first part, the attenuation is strongly dependence on properties of coupling material which was viscous oil and became less viscous at low temperature, thus the attenuation was increased very quickly when the temperature decreased. In the second part, because the viscosity of the coupling material is very good with its gel state and the ultrasonic longitudinal wave could easily propagate through this layer with small absorption, the attenuation could be only effected by properties of sample material and it should be depended on $C_{\text {longitudinal }}^{-3}$ [7]. However, the change of $C_{\text {longitudinal }}$ 
is small when temperature increased from 15 to $50{ }^{\circ} \mathrm{C}$ (Fig. 4); therefore, it is difficult to observe this dependence clearly.

\section{CONCLUSION}

In this research, the temperature dependence of ultrasonic waves transmitted in 1018 low carbon steel were determined. When the temperature changed from 0 to $50{ }^{\circ} \mathrm{C}$, the velocities of the ultrasonic longitudinal wave and ultrasonic shear wave decreased. The experimental temperature dependent coefficients of the ultrasonic longitudinal wave and ultrasonic shear wave were obtained to be -0.80 and $-0.45 \mathrm{~m} / \mathrm{s} .{ }^{\circ} \mathrm{C}$, respectively. These results agreed well to the theoretical assumption and the results of other researches. Furthermore, the attenuation of the ultrasonic longitudinal wave was also studied. Although the dependence of the temperature attenuation is complicated, it is believed that the coupling material in the direct contact affects much on the attenuation. This ultrasonic attenuation is very sensitive, therefore, it could be taken into account in practical testing.

\section{ACKNOWLEDGMENTS}

Financial supports of Project No. TN-13-09 and Project B No. QG.12.02 of VNU university of Science - Vietnam National University Hanoi are gratefully acknowledged.

\section{REFERENCES}

[1] V. H. C. D. Albuquerque, J. M. R. S. Tavares, and L. M. P. Durão, Journal of Composite Materials 44(9) (2010) 1139.

[2] F. Mabrouki, M. Genest, G. Shi, and A. Fahr, NDT \& E International 42(7) (2009)

[3] L. Schmerr, and J.-S. Song, Ultrasonic Nondestructive Evaluation Systems: Models and Measurements, (2007). 602.

[4] L. H. Le, C. Zhang, D. Ta, and E. Lou, Ultrasonics, 50(1) (2010)

[5] D. A. Ta, K. Huang, W. Q. Wang, Y. Y. Wang, and L. H. Le, Ultrasonics, 44 (2006) e279.

[6] L. H. Le, Y. J. Gu, Y. Li, and C. Zhang, Applied Physics Letters, 96(11) (2010)

[7] D. Singh, D.K. Pandey, P.K. Yadawa, and A.K. Yadav, Cryogenics, 49(1) (2009)

[8] A. I. H. Committee, Properties and Selection: Irons, Steels, and High-performance Alloys, 1, ASM International, (1990).

[9] A. Ruiz, N. Ortiz, A. Medina, J.Y. Kim, and L.J. Jacobs, NDT \& E International, 54 (2013)

[10] V. L. d. A. Freitas, V. H. C. d. Albuquerque, E. d. M. Silva, A. A. Silva, and J. M. R. S. Tavares, Materials Science and Engineering: A, 527(16-17) (2010)

[11] C. Yan, W. Guan, Z. Gao, W. Chen, and Y. Tao, Journal of Pressure Equipment and Systems 3 (2005) 54.

[12] Zenghua, L., Z. Jichen, W. Bin, and H. Cunfu, Chinese Journal of Mechanical Engineering 24(3) (2011) 487.

[13] Ltd, A.D.C.; http://www.aandd.jp/products/test_measuring/ndt/ad3213ex.html.

[14] D. T. Kien, and D.T. Thong, VNU Journal of Mathematics - Physics, 30(1) (2014) 50.

[15] F. Lanza di Scalea and S. Salamone, The Journal of the Acoustical Society of America 124(1) (2008) 161.

[16] J. C. Dodson, and D. J. Inman, Ultrasonics, 53(3) (2013) 677-85, doi:10.1016/j.ultras.2012.10.007

[17] V. Rajendran, N. Palanivelu, and B. K. Chaudhuri, Measurement, 38(3) (2005) 248-256

[18] M. Molero, I. Segura, S. Aparicio, M.G. Hernandez, and M.A. Izquierdo, Ultrasonics, 50(8) (2010) 824-828

[19] P. Palanichamy, A. Joseph, T. Jayakumar, and B. Raj, NDT \& E International, 28(3) (1995) 179-185

[20] N. Guo, M. K. Lim, and T. Pialucha, Journal of Nondestructive Evaluation, 14(1) (1995) 9-19. 